\title{
Das Eigentum als nudum ius im Bürgerlichen Recht
}

Kritische Würdigung eines juristischen Fabelwesens

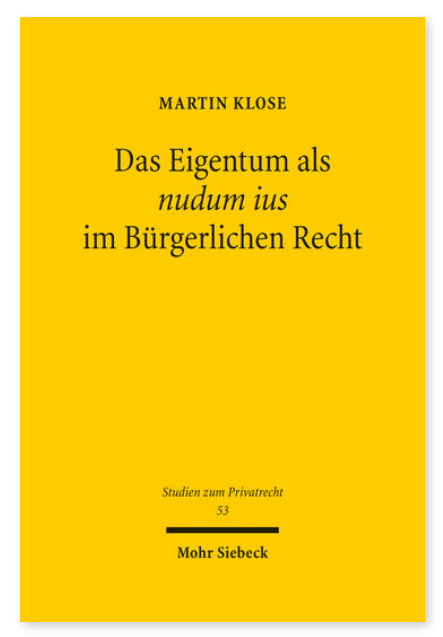

2016. XIII, 230 Seiten. StudPriv 53

ISBN 978-3-16-154849-9

DOI 10.1628/978-3-16-154849-9

eBook PDF $94,00 €$

ISBN 978-3-16-154622-8

Leinen $94,00 €$
Der Eigentümer einer Sache kann grundsätzlich nach Belieben mit ihr verfahren und andere von jeder Einwirkung ausschließen. In einigen Konstellationen des Bürgerlichen Rechts wird diese Rechtsmacht jedoch massiv beschränkt. Exemplarisch sind die Verjährung der Vindikation und die unbestellte Warenlieferung zu nennen. Martin Klose geht zum einen der Frage nach, was dem Eigentümer in einem solchen Fall von seinem Recht verbleibt, um hieraus allgemeine Lehren für die Struktur des Sacheigentums abzuleiten. Zum anderen untersucht er, inwieweit die Beschränkungen des Eigentums jeweils verfassungsrechtlich legitim sind.

Martin Klose Geboren 1985; Studium der Rechtswissenschaften an der Johannes Gutenberg-Universität Mainz; Rechtsreferendariat in Wiesbaden und Frankfurt am Main; Wissenschaftlicher Mitarbeiter am Lehrstuhl für Bürgerliches Recht, Arbeits- und Handelsrecht sowie Rechtsphilosophie in Augsburg; seit 2016 Akademischer Rat a. Z. ebenda.

Jetzt bestellen:

https://mohrsiebeck.com/buch/das-eigentum-als-nudum-ius-im-buergerlichen-recht-9783161548499?no_cache=1 order@mohrsiebeck.com

Telefon: +49 (0)7071-923-17

Telefax: +49 (0)7071-51104 